Article

\title{
Citrulline Supplementation Improves Organ Perfusion and Arginine Availability under Conditions with Enhanced Arginase Activity
}

\author{
Karolina A.P. Wijnands ${ }^{1, *}$, Dennis M. Meesters ${ }^{1}$, Kevin W.Y. van Barneveld ${ }^{1}$, \\ Ruben G.J. Visschers ${ }^{1}$, Jacob J. Briedé ${ }^{2}$, Benjamin Vandendriessche ${ }^{3,4}$, Hans M.H. van Eijk ${ }^{1}$, \\ Babs A.F.M. Bessems ${ }^{1}$, Nadine van den Hoven ${ }^{1}$, Christian J.H. von Wintersdorff ${ }^{1}$, \\ Peter Brouckaert $^{3,4}$, Nicole D. Bouvy ${ }^{1}$, Wouter H. Lamers ${ }^{5}$, Anje Cauwels ${ }^{3,4}$ and Martijn Poeze ${ }^{1}$
}

1 Department of Surgery, NUTRIM School for Nutrition, Toxicology and Metabolism, Maastricht University Medical Center, Maastricht 6200 MD, The Netherlands;

E-Mails: d.meesters@maastrichtuniversity.nl (D.M.M.);

k.vanbarneveld@maastrichtuniversity.nl (K.W.Y.B.);

r.visschers@maastrichtuniversity.nl (R.G.J.V.); hmh.vaneijk@maastrichtuniversity.nl (H.M.H.E.); imnoteviliam@hotmail.com (B.A.F.M.B.); n.vandenhoven@student.maastrichtuniversity.nl (N.H.); c.von.wintersdorff@mumc.nl (C.J.H.W.);n.bouvy@mumc.nl (N.D.B.);

m.poeze@maastrichtuniversity.nl (M.P.)

2 Department of Toxicogenomics, GROW School for Oncology and Developmental Biology, Maastricht University Medical Center, Maastricht 6200, The Netherlands;

E-Mail: j.briede@maastrichtuniversity.nl

3 Department of Molecular Biomedical Research, VIB, Ghent B-9000, Belgium;

E-Mails: benjamin.vandendriessche@dmbr.ugent.be (B.V.);

Peter.Brouckaert@dmbr.vib-ugent.be (P.B.); anje.cauwels@vib-ugent.be (A.C.)

Department of Biomedical Molecular Biology, Ghent University, Ghent B-9000, Belgium

5 Department of Anatomy \& Embryology, Maastricht University Medical Center, Maastricht 6200, The Netherlands; E-Mail: wh.lamers@maastrichtuniversity.nl

* Author to whom correspondence should be addressed; E-Mail: n.wijnands@maastrichtuniversity.nl; Tel.: +31-43-387-1956; Fax: +31-43-387-5473.

Received: 12 May 2015 / Accepted: 18 June 2015 / Published: 29 June 2015

\begin{abstract}
Enhanced arginase-induced arginine consumption is believed to play a key role in the pathogenesis of sickle cell disease-induced end organ failure. Enhancement of arginine availability with L-arginine supplementation exhibited less consistent results; however, L-citrulline, the precursor of L-arginine, may be a promising alternative. In this study, we
\end{abstract}


determined the effects of L-citrulline compared to L-arginine supplementation on arginine-nitric oxide (NO) metabolism, arginine availability and microcirculation in a murine model with acutely-enhanced arginase activity. The effects were measured in six groups of mice ( $n=8$ each) injected intraperitoneally with sterile saline or arginase (1000 IE/mouse) with or without being separately injected with L-citrulline or L-arginine $1 \mathrm{~h}$ prior to assessment of the microcirculation with side stream dark-field (SDF)-imaging or in vivo NO-production with electron spin resonance (ESR) spectroscopy. Arginase injection caused a decrease in plasma and tissue arginine concentrations. L-arginine and L-citrulline supplementation both enhanced plasma and tissue arginine concentrations in arginase-injected mice. However, only the citrulline supplementation increased NO production and improved microcirculatory flow in arginase-injected mice. In conclusion, the present study provides for the first time in vivo experimental evidence that L-citrulline, and not L-arginine supplementation, improves the end organ microcirculation during conditions with acute arginase-induced arginine deficiency by increasing the NO concentration in tissues.

Keywords: arginase; arginine; citrulline; microcirculation; nitric oxide

\section{Introduction}

Sickle cell disease can be affected by acute life-threatening complications, such as recurrent vaso-occlusive events, pulmonary hypertension and severe hemolysis [1,2]. In an acute crisis with intravascular hemolysis [3,4], arginase is released in large quantities by damaged red blood cells $[1,4,5]$. This arginase rapidly consumes the locally-available arginine, leading to a diminished production of the main vasodilator of the microcirculation, nitric oxide (NO) production [6], which contributes to an impaired microvascular flow, resulting in end-organ damage [1,2]. Therefore, arginase-induced arginine deficiency is believed to play a key role in the pathogenesis of sickle cell disease-induced end-organ failure $[2,7,8]$. Other mechanisms possibly contributing to the decreased microvascular flow are increased oxidative stress and the release of hemoglobin from the damaged red blood cells, which consumes NO [3,4]. Therefore, supplementing arginine to restore the depleted arginine pools was suggested to be a good therapeutic approach to treat end-organ damage in sickle cell disease [9].

Previous studies with L-arginine supplementation in transgenic sickle cell mice showed a reduction in oxidative stress and hemolysis and increased NOx concentrations [10,11]. However, clinical results using L-arginine were less consistent. In a non-controlled patient study, L-arginine supplementation reduced pulmonary pressure, but also tended to further increase arginase activity [5]. Another study similarly found that L-arginine supplementation increased arginase activity, but found no increase in NOx concentrations [7]. A third study showed highly variable changes in exhaled NO concentrations during L-arginine supplementation, while no effects on clinical parameters were found [12]. Finally, in a study comparing L-arginine with a phosphodiesterase inhibitor, no clinical benefits were found during L-arginine supplementation [13], suggesting no extra NO production. In these patients, ornithine concentrations increased significantly, suggesting an enhanced arginase activity, while citrulline concentrations were unchanged. 
Instead of L-arginine, its precursor, L-citrulline, which is endogenously produced in the gut $[14,15]$, may be the preferred substrate to enhance intracellular arginine availability by enhancing arginine de novo synthesis and NO production in pathophysiological conditions with increased arginase activity, resulting in enhanced arginine consumption, such as sickle cell disease [16] or endotoxemia [17]. As for endotoxemia, another condition with high arginase activity, L-citrulline supplementation resulted in increased NO production and better microvascular flow than L-arginine supplementation [17]. In sickle cell disease, only one non-controlled pilot study showed that citrulline supplementation enhanced the arginine availability and relieved fatigue and dyspnea in these patients [16]. However, the effects of L-citrulline supplementation on the microcirculatory flow and tissue NO production have not been determined or compared to that of L-arginine supplementation in a preclinical setting in experimental conditions with an acute increase of arginase $[16,18]$. We, therefore, prior to a clinical study, determined the effect of L-citrulline compared to L-arginine supplementation on arginine-NO metabolism, arginine availability in blood, kidney, liver and jejunal tissue and the microcirculation in the jejunum of mice with an acutely-enhanced circulating concentration of arginase.

\section{Material and Methods}

\subsection{Animals}

Forty-eight male C57BL/6J mice (25-30 grams) were bred at the Department for Molecular Biomedical Research of Ghent University. Mice were individually housed and subjected to standard 12-h light-dark cycle periods. Mice were fed standard lab chow and water ad libitum. Mice adapted to the laboratory environment for 7 days prior to the start of the experiments. The study protocol was approved by the Committee on the Ethics of Animal Experiments of Ghent University (approval number EC2012-028).

\subsection{Experimental Protocol}

This experimental model, with an acute arginine-deficient state induced by intraperitoneal (i.p.) arginase injection, was developed to determine the preferential substrate, L-citrulline or L-arginine supplementation, on arginine availability, tissue NO production and microcirculation. The arginase concentration used in this study, $1000 \mathrm{IE} / 25 \mathrm{~g}$, was based on previous experience in our group, resulting in a $>60 \%$ reduction in plasma arginine concentrations [19], and on clinical studies in which plasma arginase activity during the steady-state phase of sickle cell disease caused a $\sim 1.5$-fold decrease in plasma arginine concentrations $[4,20]$.

At $0 \mathrm{~h}$, mice were injected intraperitoneally with sterile saline $(\mathrm{NaCl} 0.9 \% ; 0.5 \mathrm{~mL})$, L-citrulline (Cit; $37.5 \mathrm{mg} ; 0.2 \mathrm{mmol}$ ) or L-arginine (Arg; $37.5 \mathrm{mg} ; 0.2 \mathrm{mmol}$ ), with or without arginase in a separate syringe and on the contralateral site injected (Sigma, St. Louis, MO, USA, 40 IE/g protein, $0.1 \mathrm{~mL}$ ). Five groups were studied: control $(n=8)$, arginase injection $(n=8)$, citrulline supplementation $(n=8)$, arginine supplementation $(n=8)$, citrulline + arginase $(n=8)$ and arginine + arginase $(n=8)$ (See Figure 1 for the experimental setup). After the injection, food was withheld, but water was provided throughout the experimental phase. One hour after the i.p. injections, spin trap agents were administered i.p. and subcutaneously (s.c.) for tissue NO production measurements ( $n=3$ per group), as described below. Mice used for microcirculatory measurements received an equal amount of sterile saline. Simultaneously, 
mice were premedicated with $0.01 \mathrm{mg} / \mathrm{kg}$ Temgesic ${ }^{\circledR}$ (Reckitt \& Colman Products LTD., Kingston-Upon Hill, U.K.) s.c.

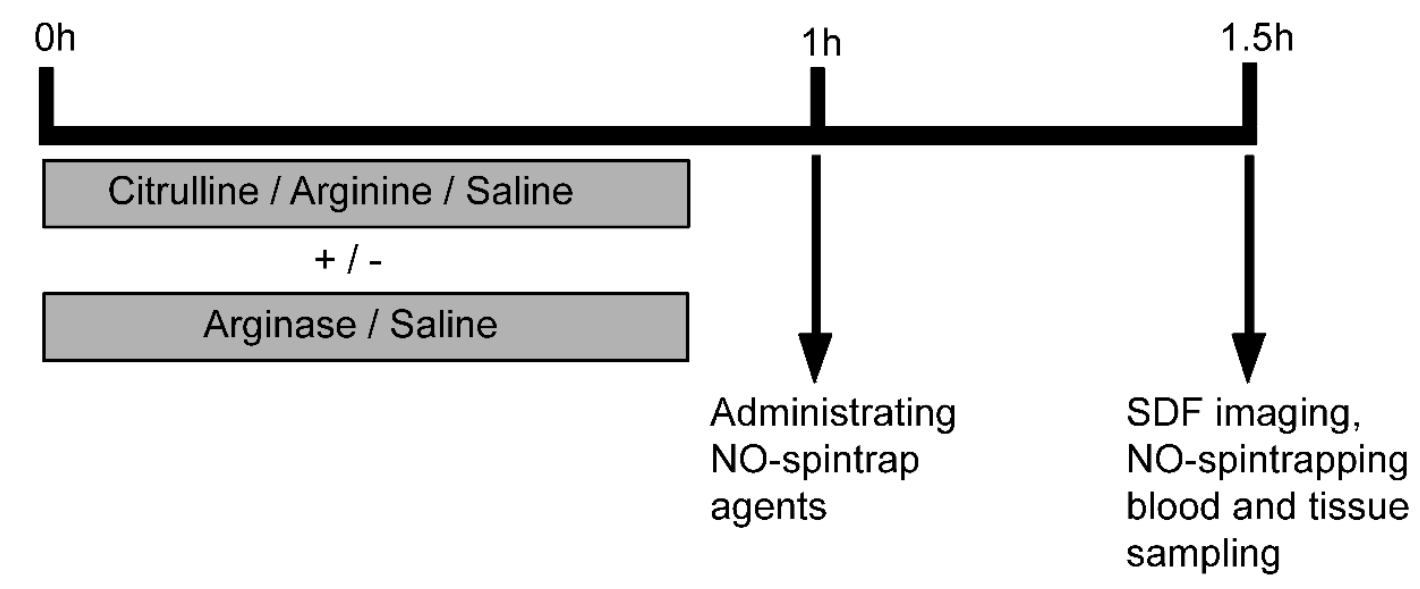

Figure 1. Experimental setup of the acute arginase model. Mice received an intraperitoneal injection with sterile saline or arginase combined with L-citrulline or L-arginine at time zero $(t=0 \mathrm{~h})$. After $1 \mathrm{~h}(t=1 \mathrm{~h})$, mice received either spin-trap agents to measure the nitric oxide (NO) production in vivo or a sterile saline injection as placebo treatment. After $1.5 \mathrm{~h}$ $(t=1.5 \mathrm{~h})$, side stream dark-field (SDF) imaging was used to quantify the microcirculation in the jejunal villi or organs were harvested to determine the formed iron-diethyldithiocarbamate (DETC) complexes as a parameter for the NO production in vivo. At the end of the experiment, blood and tissue samples were harvested for amino acid determination.

One and a half hours after the initial injection, anesthesia was induced with $4 \%$ isoflurane (Abbott Laboratories LTD, Maidenhead, U.K.). During the measurements of the tissue NO production and microcirculatory analysis in the jejunal mucosa with a side stream dark-field (SDF) imager, anesthesia was maintained with $2 \%$ isoflurane. All imaging experiments were done by an experienced investigator, who was blinded to the treatment allocation. Images were analyzed by 2 independent, experienced researchers, both blinded to the treatment.

Throughout the experiment, body temperature was maintained at $37{ }^{\circ} \mathrm{C}$, using an infrared heating lamp with a temperature controller connected to a rectal probe. At the end of the experiment, blood was sampled via cardiac puncture, after which the animals were euthanized by cervical dislocation.

\subsection{Amino Acid Analysis}

After deproteinization, plasma and tissue (jejunum, liver and kidney) amino acid concentrations were determined with a fully-automated liquid chromatography-mass spectrometry system (LC-MS, Thermoquest LTQ, Veenendaal, The Netherlands) as described before [17,21]. Jejunal, liver and kidney tissue were used to determine the role of the gut-liver-renal axis in an acute arginine-deficient state. To determine the arginine availability in plasma and tissue, the arginine availability index (AAI) ((arginine)/((ornithine) + (lysine))) was calculated. This index is based on the uptake in cells of arginine, ornithine and lysine by the $\mathrm{y}^{+}$transporter system and provides an indication of the relative available arginine for metabolic pathways [22]. The arginine transporter $\mathrm{y}^{+}$consists of four different types of cationic amino acid transporters (CATs); CAT-1, CAT-2a and CAT-2b, CAT-3 and CAT-4 [23,24]. Only CAT-1 and 
CAT-2b have a high affinity for cationic amino acids, such as arginine and citrulline; therefore, the influence of CAT-2a, CAT-3 and CAT-4 is negligible in this study. CAT-1 is expressed in almost all adult cells during physiological conditions [25], whereas CAT-2b is only expressed after induction with cytokines or lipopolysaccharide (LPS) treatment in inflammatory cells $[23,26]$, which was not present in this study. Figure 2 provides a schematic overview of the relevant metabolic pathways of arginine.

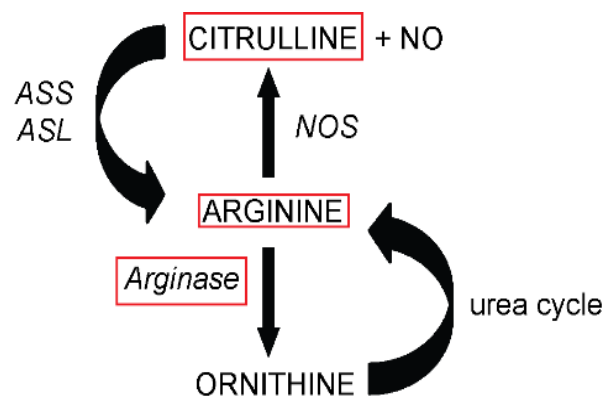

Figure 2. Schematic overview of the relevant metabolic pathways of arginine. Abbreviations: NO, nitric oxide; NOS, nitric oxide synthase; ASS, argininosuccinate synthase; ASL, argininosuccinate lyase.

\subsection{In Vivo Tissue NO Measurements}

The in vivo NO production in jejunum, liver and kidney was determined in tissue samples of mice $(n=18)$ injected with spin-trap agents, as described previously [17]. Briefly, mice were injected s.c. in the scruff of the neck with a mixture of $\mathrm{FeSO}_{4} \cdot 7 \mathrm{H}_{2} \mathrm{O}(37.5 \mathrm{mg} / \mathrm{kg})$, sodium citrate $(190 \mathrm{mg} / \mathrm{kg})$ and i.p. with diethyldithiocarbamate (DETC, $500 \mathrm{mg} / \mathrm{kg}$ ) $30 \mathrm{~min}$ prior to sacrifice [27]. NO is trapped with $\mathrm{Fe}^{2+}$-dithiocarbamate, an mono-nitrosyl iron complex (MNIC), and measured with electron spin resonance (ESR) spectroscopy, as described [17,27]. NO concentrations were calculated from the height of the three-line NO amplitude using Bruker WINEPR software [17,27].

\subsection{Jejunal Microcirculation Measurements with SDF Imaging}

Microscopic visualization of the intestinal mucosal microcirculation in the jejunal villi with the SDF-imager (Microscan, Amsterdam, The Netherlands) [28,29] was described in detail [17] and chosen because the gut is easily accessible and a frequently affected end organ [30]. In brief, a small incision was made in the jejunum to visualize the jejunal villi. A specially-designed stand was used to stabilize the SDF-imager and to avoid pressure on the jejunal villi during the measurements. The microcirculation, determined as the total number of perfused vessels per villus, was analyzed using Automated Vascular Analysis software 3.0 (Microscan, Amsterdam, The Netherlands), adjusted according to De Backer et al. [31-33]. Furthermore, the average microvascular flow index (MFI), a semiquantitative assessment of the predominant type of flow in the villi, was determined in the four quadrants of the image ( $0=$ absent, $1=$ intermittent, with at least $50 \%$ of the time having no flow, $2=$ sludging, $3=$ normal or $4=$ hyperdynamic flow) [32]. All imaging experiments were performed by an experienced investigator, and images were analyzed by two independent, blinded, experienced researchers. 


\subsection{Statistical Analysis}

Statistical analysis of the data was performed using SPSS 19.0 (SPSS, Chicago, IL, USA). In the experiment, comparisons were made between control and arginase groups to test the effect of arginase treatment. The control group was also compared with the citrulline- and arginine-supplemented groups to determine the effect of L-citrulline or L-arginine supplementation during the control condition. Finally, the citrulline + arginase group and the arginine + arginase group were compared with the arginase group to test the effect of L-citrulline or L-arginine supplementation during an acute arginine-deficient state. In case of a Gaussian distribution, one-way ANOVA with post hoc Bonferroni correction between groups was used. A two-sided $p<0.05$ was considered as statistically significant. Data are represented as the mean and standard error of the mean (SEM).

\section{Results}

\subsection{Improved Plasma Amino Acid Concentrations after Citrulline Supplementation in} Arginase-Treated Animals

Arginase injection resulted in a $<35 \%$ reduction of plasma arginine concentrations compared to control animals $(p<0.0001$; Figure 3A; see Supplementary Table S1 for normalized values of all amino acids). As expected, both L-arginine and L-citrulline supplementation resulted in higher plasma arginine and citrulline concentrations during control conditions (Figure 3A,B). L-citrulline supplementation mediated a $>4$-fold significant increase in plasma arginine concentration in arginase-treated animals, whereas arginine supplementation was unable to mediate a significant increase in plasma arginine concentration in arginase-injected animals (Figure 3A).

\section{Plasma}

A

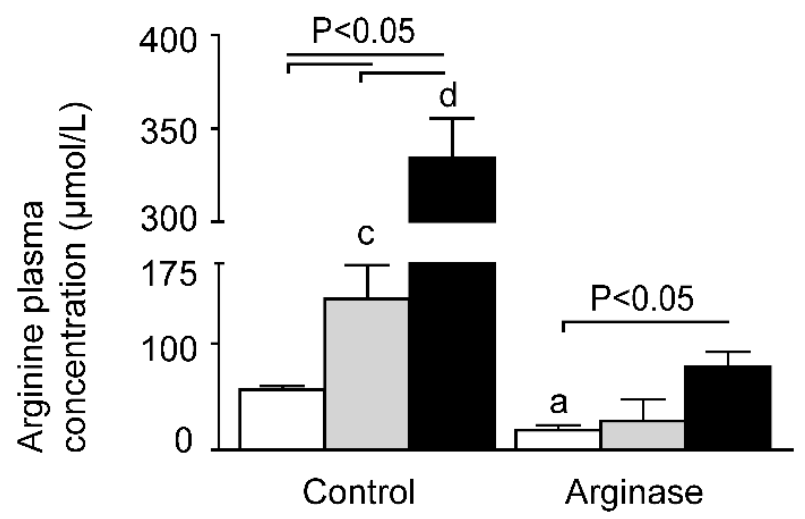

B

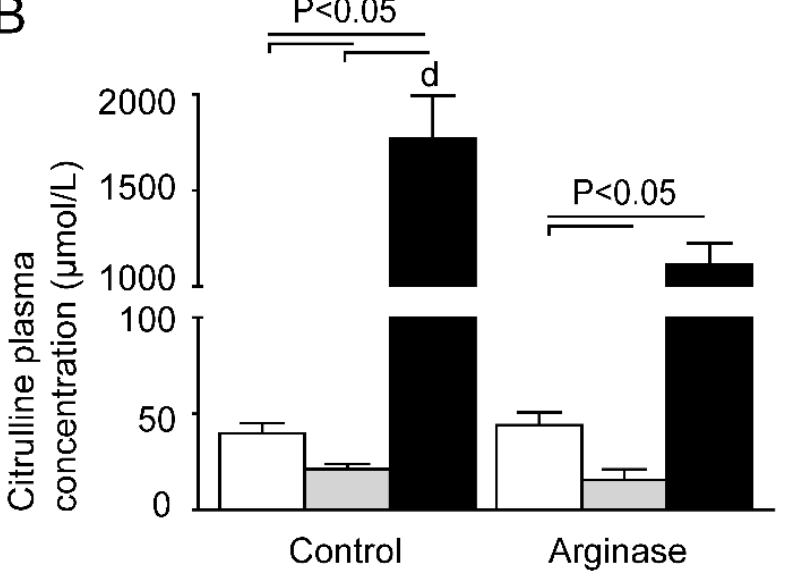

$\square \mathrm{NaCl} \square$ Arginine $\square$ Citrulline

Figure 3. Cont. 


\section{Plasma}
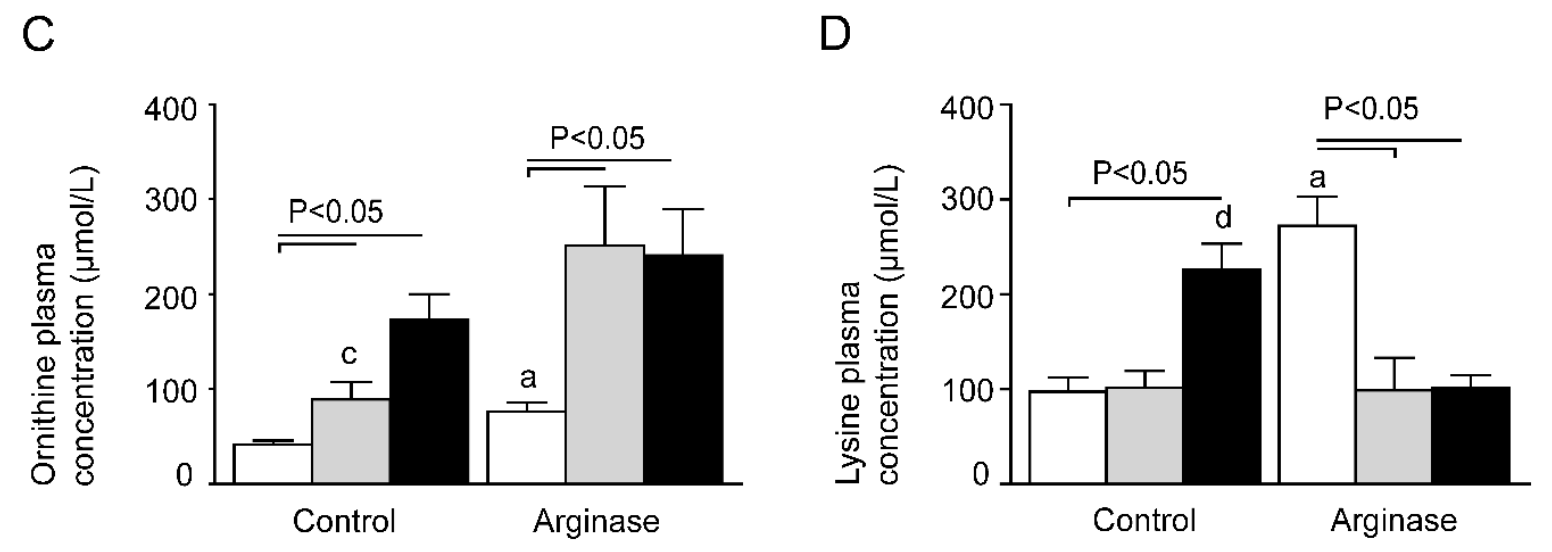

$\square \mathrm{NaCl} \square$ Arginine $\square$ Citrulline

Figure 3. Effect of L-arginine or L-citrulline supplementation on plasma amino acid concentrations in control and arginase treated mice. (A) Plasma arginine concentrations during basal and arginase-treated conditions with or without citrulline or arginine; (B) plasma citrulline concentration in all treated groups; $(\mathbf{C})$ ornithine concentrations during basal and arginase-treated conditions; (D) lysine concentrations in plasma were measured with HPLC. Plasma concentrations are displayed as $\mu \mathrm{mol} / \mathrm{L}$. Significance: ${ }^{\mathrm{a}} p<0.05$ vs. control; ${ }^{\mathrm{b}} p<0.05 v s$. arginine; ${ }^{\mathrm{c}} p<0.05 v s$. arginine + arginase; ${ }^{\mathrm{d}} p<0.05 v s$. citrulline + arginase.

In parallel to the decreased plasma arginine concentrations in arginase-treated animals, ornithine concentrations were significantly higher (Figure 3C), indicating the conversion of arginine to ornithine by the injected arginase. Both L-citrulline and L-arginine significantly increased ornithine concentrations in arginase-treated animals. Interestingly, citrulline concentrations were significantly lower in arginase-treated animals supplemented with L-arginine than in animals treated with arginase alone (Figure 3B).

\subsection{Depleted Tissue Amino Acid Concentrations Were Restored by Citrulline and Arginine Supplementation}

Next, we investigated the tissue amino acid concentrations in gut, liver and kidney (Figures 4-6). These organs play an important role in arginine and citrulline metabolism and are suggested to be involved in sickle cell-induced end organ failure. After arginase infusion, the intestinal arginine concentration was significantly lower $(\sim 55 \%)$ than in control mice (Figure 4A). L-arginine and L-citrulline supplementation resulted in $\sim 5$-fold and $\sim 4$-fold higher jejunal arginine concentrations, respectively, compared to mice infused with arginase alone (Figure 4A). Citrulline supplementation resulted in a significantly higher tissue citrulline concentration in the citrulline-treated and citrulline + arginase-treated mice (Figure 4B). Furthermore, the intestinal ornithine concentration was higher in arginase-treated than control mice, but also in L-citrulline- and L-arginine-supplemented mice than in control or arginase-treated mice (Figure 4C) 


\section{Jejunal Tissue}

A

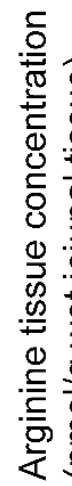

C

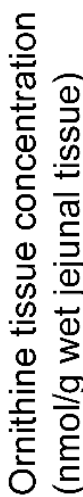

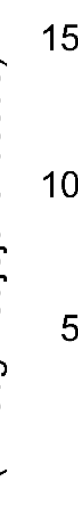

1500
1000
500
0

0

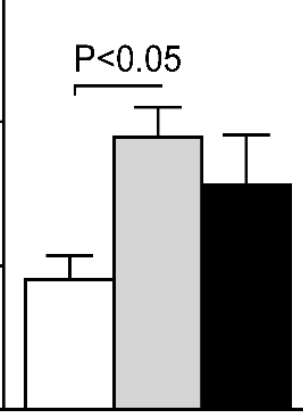

Control

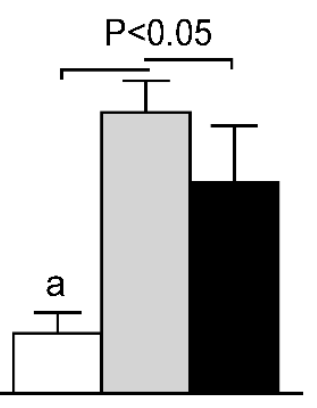

Arginase
$\mathrm{B}$

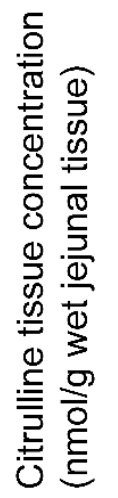

D

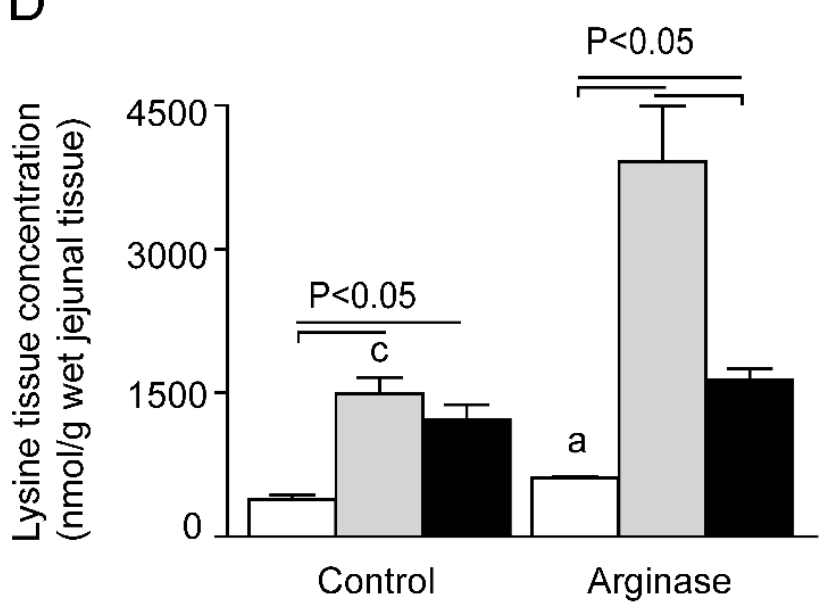

Figure 4. Effect of L-arginine or L-citrulline supplementation on jejunal tissue amino acid concentrations in control and arginase-treated mice. Jejunal tissue concentrations during basal and arginase-treated conditions of (A) arginine, (B) citrulline, (C) ornithine and (D) lysine were measured with High Performance Liquid Chromatography (HPLC). Tissue concentrations are displayed as nmol/g wet tissue). Significance: ${ }^{\mathrm{a}} p<0.05$ vs. control; ${ }^{\mathrm{b}} p<0.05$ vs. arginine; ${ }^{\mathrm{c}} p<0.05 v s$. arginine + arginase; ${ }^{\mathrm{d}} p<0.05 v s$. citrulline + arginase.

In liver, arginase treatment resulted in a $\sim 50 \%$ lower tissue arginine concentration than measured in control mice (Figure 5A). As was to be expected in view of its very high arginase content, liver arginine content is $<10 \%$ of that in the gut. L-citrulline supplementation did not result in higher tissue arginine concentrations in the liver of control or arginase-treated mice (Figure 5A), although L-citrulline supplementation increased the liver citrulline concentration (Figure 5B). L-arginine supplementation resulted in comparable arginine concentrations in control animals, but in arginase-treated and arginine-supplemented mice, liver arginine concentrations were significantly lower than in mice that were treated with arginase only (Figure 5A). Interestingly, arginase treatment alone was not associated with increased ornithine 
concentrations in liver tissue, although L-citrulline- and L-arginine-supplemented mice both had significantly higher ornithine concentrations in liver tissue (Figure 5C).

\section{Liver Tissue}

A

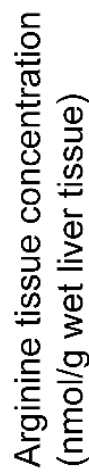

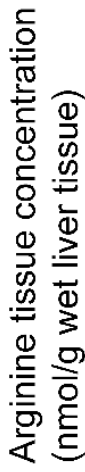

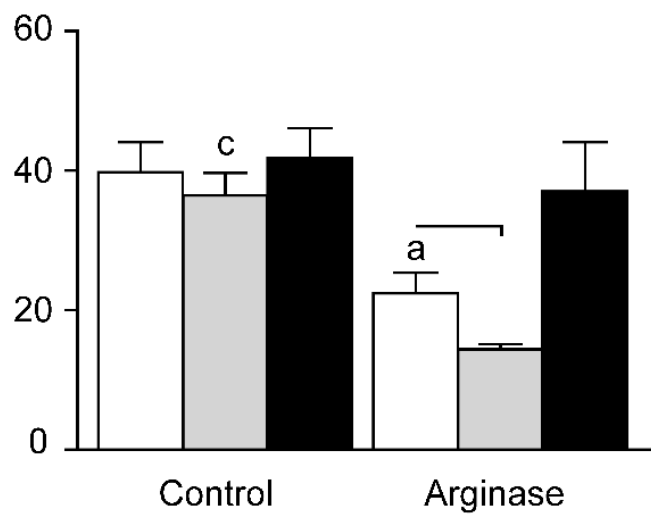

C

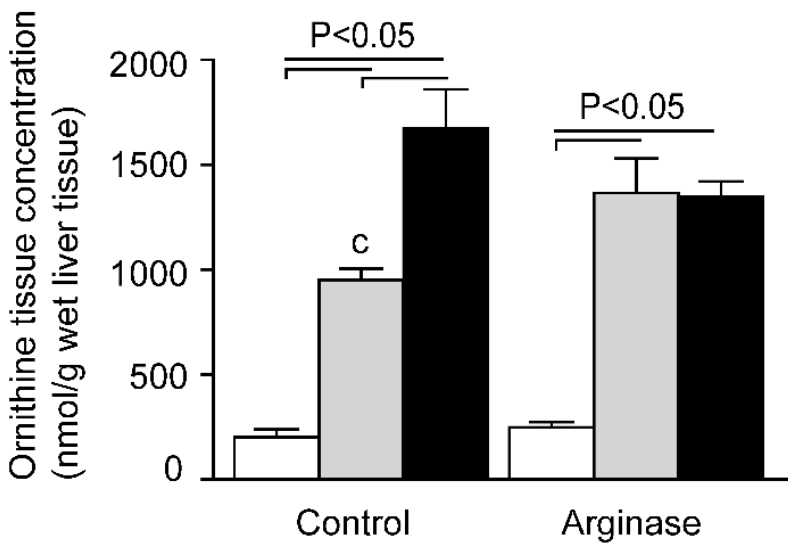

B
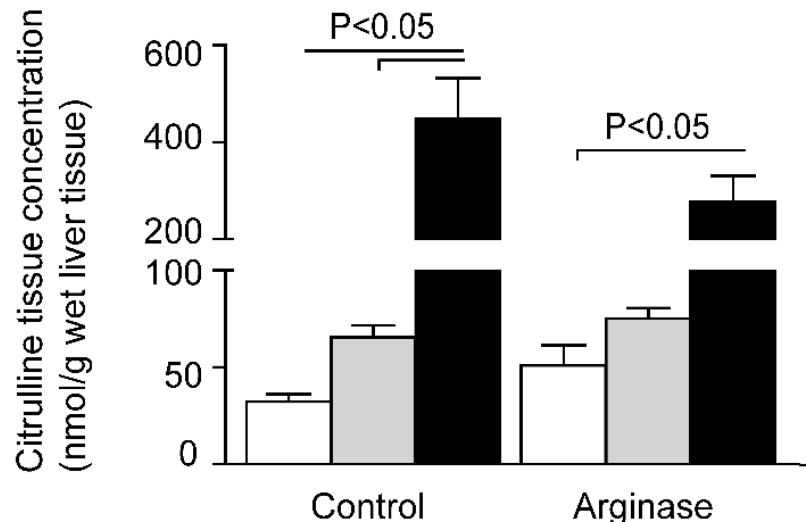

$\mathrm{D}$

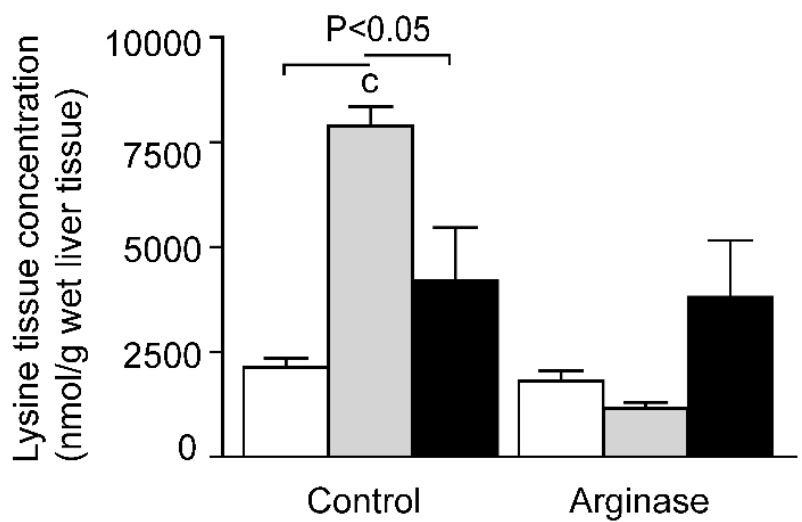

$\mathrm{NaCl} \square$ Arginine $\square$ Citrulline

Figure 5. Effect of L-arginine or L-citrulline supplementation on liver tissue amino acid concentrations in control and arginase-treated mice. Liver tissue concentrations during basal and arginase-treated conditions of (A) arginine, (B) citrulline, $(\mathbf{C})$ ornithine and (D) lysine were measured with HPLC. Tissue concentrations are displayed as $\mathrm{nmol} / \mathrm{g}$ wet tissue). Significance: ${ }^{\mathrm{a}} p<0.05 v$ s. control; ${ }^{\mathrm{b}} p<0.05 v s$. arginine; ${ }^{\mathrm{c}} p<0.05 v s$. arginine + arginase; ${ }^{\mathrm{d}} p<0.05 v s$. citrulline + arginase.

Comparable to the gut and liver, arginase infusion also significantly lowered renal arginine concentrations (Figure 6A) and increased ornithine levels (Figure 6C). L-arginine supplementation increased renal arginine concentrations, both with and without arginase treatment, compared to their respective control conditions (Figure 6A). L-citrulline treatment resulted in increased citrulline concentrations (Figure $6 \mathrm{~B}$ ) and a $\sim 35$-fold increase in arginine concentrations, irrespective of the presence of arginase (Figure 6A). Besides the enhanced arginine concentrations, L-arginine and L-citrulline 
supplementation in arginase-treated mice resulted in significantly higher renal ornithine concentrations; $\sim 25$-fold in the arginine + arginase group and $\sim 8$-fold in the citrulline + arginase group (Figure $6 \mathrm{C}$ ). L-arginine supplementation did not result in higher intracellular citrulline concentrations in the kidney.

\section{Renal Tissue}

A

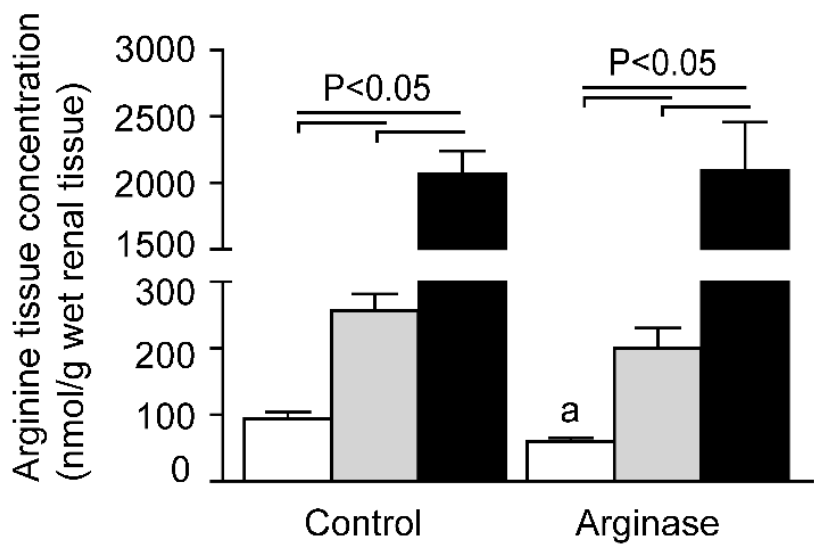

C

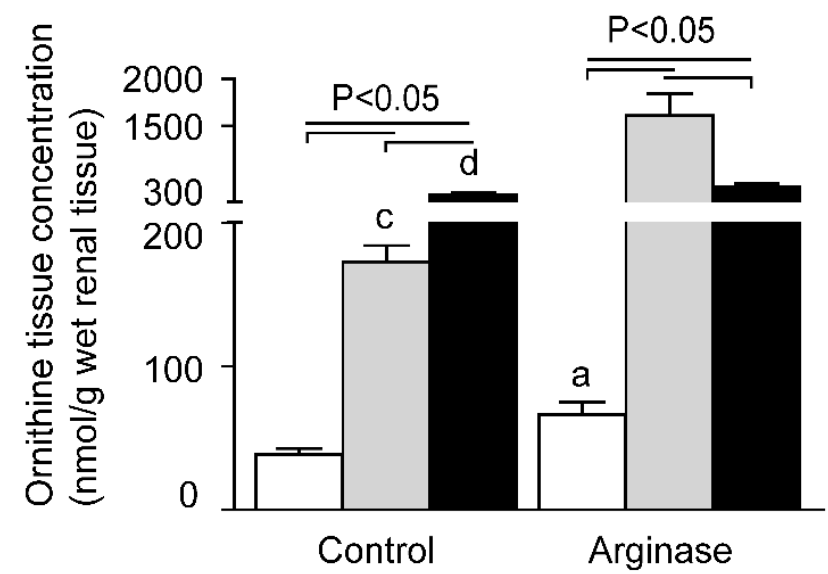

$\mathrm{B}$

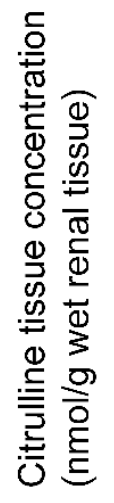

$\mathrm{D}$

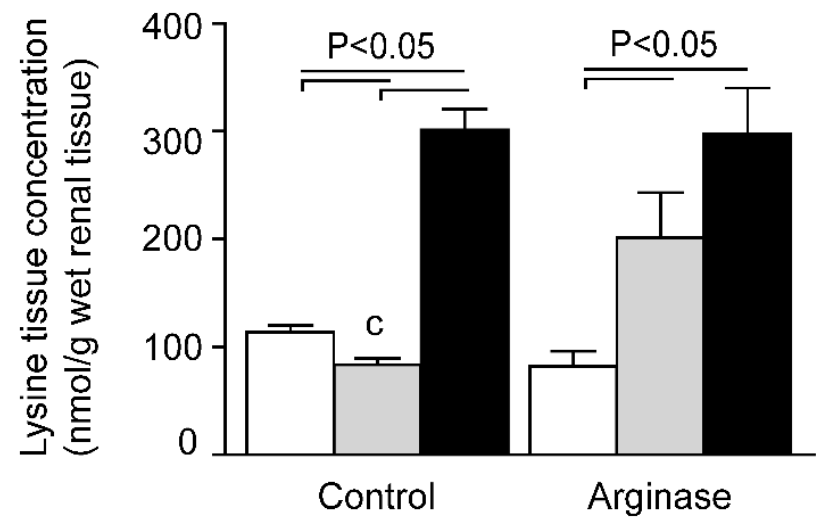

$\square \mathrm{NaCl} \square$ Arginine $\square$ Citrulline

Figure 6. Effect of L-arginine or L-citrulline supplementation on renal tissue amino acid concentrations in control and arginase-treated mice. Renal tissue concentrations during basal and arginase-treated conditions of (A) arginine, (B) citrulline, (C) ornithine and (D) lysine were measured with HPLC. Tissue concentrations are displayed as $\mathrm{nmol} / \mathrm{g}$ wet tissue). Significance: ${ }^{\mathrm{a}} p<0.05 v$ s. control; ${ }^{\mathrm{b}} p<0.05 v s$. arginine; ${ }^{\mathrm{c}} p<0.05 v s$. arginine + arginase; ${ }^{\mathrm{d}} p<0.05$ vs. citrulline + arginase.

Together with arginine and ornithine, lysine is one of the major basic amino acids in plasma. Since it is an essential amino acid, changes in concentration only reflect changes in transport and degradation. The lysine concentration in plasma was significantly higher in arginase-infused mice than in control, arginase + arginine- and arginase + citrulline-supplemented mice (Figure 3D). L-citrulline-supplemented control mice also exhibited a significantly higher plasma lysine concentration than control mice (Figure 2D). 
The lysine concentrations in jejunal tissue increased $\sim 3$-fold in arginine- and citrulline-supplemented mice compared to the control (Figure 4D). Lysine increased $\sim 2$-fold in arginase-infused mice compared to the control. L-arginine or L-citrulline supplementation in arginase-infused mice resulted in a $\sim 6.5$-fold and $\sim 2.5$-fold increase in lysine concentration, respectively. Lysine concentration in liver tissue was only significantly enhanced in the arginine-supplemented group compared to the control (Figure 5D). The renal lysine concentration increased $\sim 3$-fold in the L-citrulline supplementation group compared to the control (Figure 6D). In contrast, arginine supplementation during control conditions resulted in a significantly decreased lysine concentration in renal tissue compared to control treated animals. L-arginine or L-citrulline supplementation in arginase-infused mice resulted in a $\sim 2.5$-fold and $\sim 3.5$-fold increased lysine concentration, respectively, compared to arginase-treated mice alone (Figure 6D).

\subsection{Arginine Availability in Plasma and Tissues of Arginase-Treated Animals}

The arginine availability index (AAI) in plasma and tissue $(($ arginine $) /(($ ornithine $)+($ lysine $)))$ assumes that the cationic amino acid arginine is transported in and out of cells in exchange for ornithine or lysine [22]. The AAI declined $\sim 8$-fold in plasma of arginase-infused and arginase + arginine-supplemented mice and $\sim$-fold in arginase + citrulline-supplemented mice (Figure 7A). The effects in tissues were less dramatic and had a clear sequence: kidney and jejunum were affected and liver not or even improved. In jejunal tissue, the AAI was significantly reduced in arginase-infused mice compared to the control, which was not enhanced by L-arginine supplementation (Figure 7B). In line with this, L-citrulline supplementation in arginase-infused mice did not result in an enhanced AAI in jejunal tissue of these mice compared to arginase-treated mice alone (Figure 7B). Liver arginine availability was low in all groups, as expected by the high arginase content in liver tissue, and was significantly lowered in the L-arginine and L-citrulline supplementation during control conditions (Figure 7C). L-arginine supplementation resulted in an increased AAI in renal tissue during control conditions (Figure 7D). Arginase infusion resulted in a significant decreased AAI in renal tissue compared to control mice (Figure 7D). This decreased AAI was even significantly more decreased by L-arginine supplementation (Figure 7D). In contrast, L-citrulline supplementation resulted in higher AAI in renal tissue in both control and arginase-treated mice (Figure 7D).

\subsection{Impaired Tissue NO Production during Acute Arginine Deficiency}

In line with the decreased arginine availability, the intestinal NO production decreased after arginase infusion (from $6.3 \pm 0.2$ to $3.0 \pm 0.6 \mathrm{pmol} \mathrm{MNIC/mg} \mathrm{jejunal} \mathrm{tissue} \mathrm{per} 30 \mathrm{~min}, p<0.001$; Figure $8 \mathrm{~A}$ ). L-citrulline supplementation in arginase-treated animals resulted in significantly higher jejunal NO production $(p<0.05$; Figure 8A). In contrast, arginine supplementation in arginase-treated animals did not result in higher NO production ( $p=0.2$; Figure $8 \mathrm{~A})$. 
A

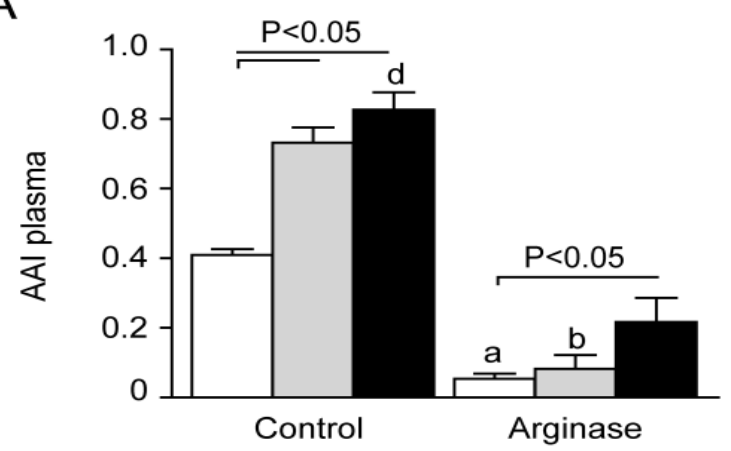

C

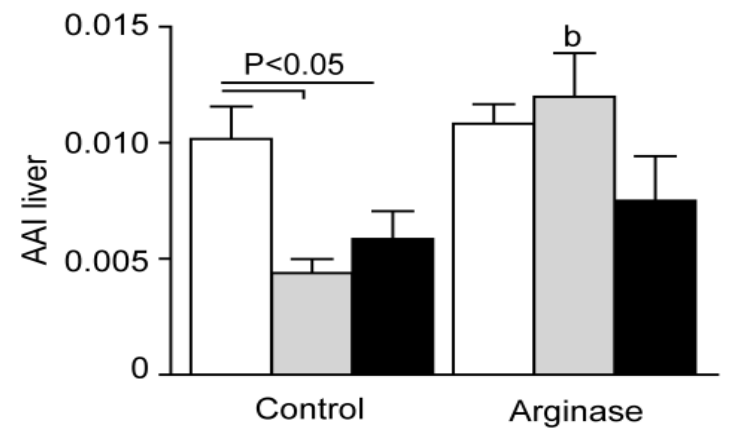

B

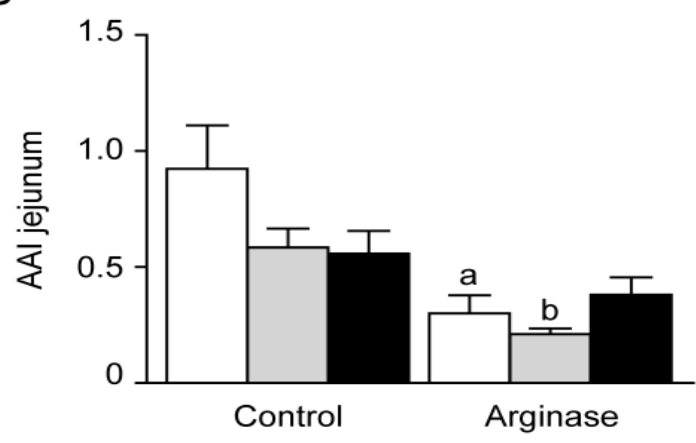

$\mathrm{D}$

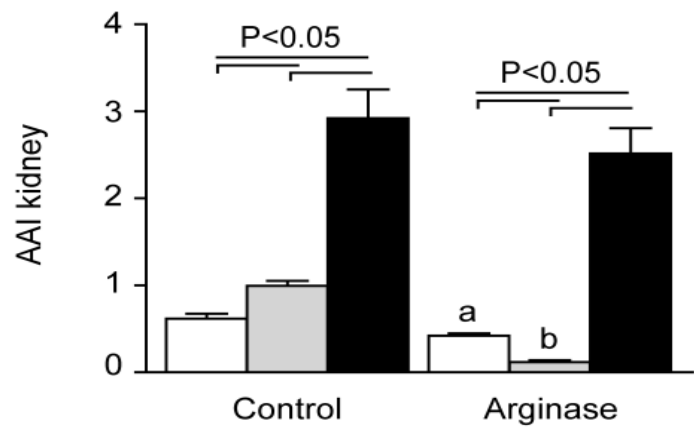

Figure 7. Plasma and tissue arginine availability in control and arginase-treated animals with L-arginine or L-citrulline supplementation. Arginine arginine availability index (AAI; (arginine) $/(($ lysine $)+($ ornithine $)))$ measured in plasma $(\mathbf{A})$, jejunal tissue $(\mathbf{B})$, liver $(\mathbf{C})$ and renal tissue (D) of control and arginase-treated animals with or without supplemented L-arginine or L-citrulline. Significance: ${ }^{\mathrm{a}} p<0.05$ vs. control; ${ }^{\mathrm{b}} p<0.05$ vs. arginine; ${ }^{\mathrm{c}} p<0.05 v s$. arginine + arginase ${ }^{\mathrm{d}} p<0.05 v s$. citrulline + arginase.

A

B
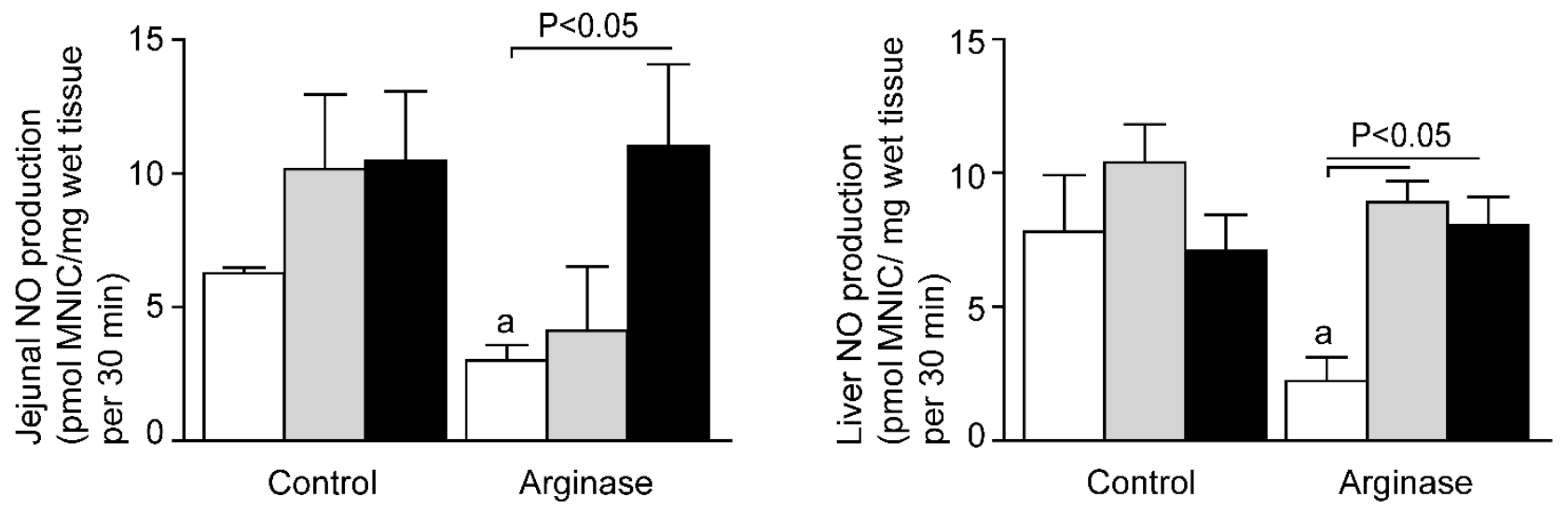

$\square \mathrm{NaCl} \square$ Arginine $\square$ Citrulline

Figure 8. Cont. 


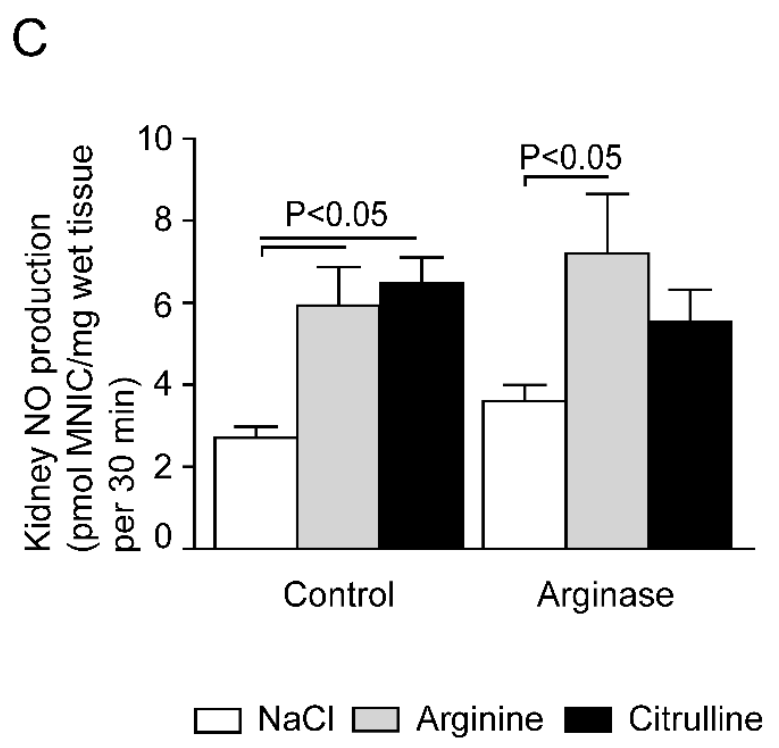

Figure 8. Tissue NO production in control and arginase-treated animals with L-arginine or L-citrulline supplementation. (A) The expected arginase-induced decrease in jejunal NO production, determined as pmol mono-nitrosyl iron complex (MNIC)/mg wet tissue, was not present in the arginase + L-citrulline-treated group, whereas in the L-arginine-treated group, the NO production was not enhanced. (B) L-citrulline and L-arginine supplementation both resulted in an enhanced NO production in the liver of arginase-treated animals. (C) Arginase infusion did not decrease the renal NO production compared to control treated animals. L-arginine supplementation significantly increased renal NO concentration in arginase-treated animals, while L-citrulline only tended to increase the NO levels. Significance: ${ }^{\mathrm{a}} p<0.05$ vs. control; ${ }^{\mathrm{b}} p<0.05$ vs. arginine; ${ }^{\mathrm{c}} p<0.05$ vs. arginine $+\operatorname{arginase} ;{ }^{\mathrm{d}} p<0.05 v s$. citrulline + arginase.

Arginase injection also resulted in a significantly lower NO production in liver (from $7.8 \pm 2.1$ to $2.2 \pm 0.9 \mathrm{pmol} \mathrm{MNIC} / \mathrm{mg}$ tissue per $30 \mathrm{~min}, p<0.05, n=3$; Figure $8 \mathrm{~B}$ ). L-citrulline and L-arginine supplementation in arginase-treated mice resulted in a significantly higher liver NO production. This NO concentration in the citrulline + arginase group was comparable to citrulline-treated control animals (Figure 8B; not significant, $n=3$ ).

Arginase injection did not result in decreased renal NO production (Figure 8C). Interestingly, only L-arginine supplementation could significantly increase renal NO production in arginase-treated animals, while L-citrulline only tended to increase the NO production. In addition, during basal conditions, the NO production in the kidney was significantly higher in both L-citrulline and L-arginine-supplemented mice than control mice (Figure 8C).

\subsection{Citrulline Supplementation in Arginase-Treated Animals Restored Jejunal Microcirculation}

To determine the effect of arginase injection on the microcirculation in one of the end organs, the microcirculation in the jejunal villi of arginase-treated mice was measured with the SDF-imager. Arginase infusion resulted in an impaired microcirculation, as deduced from a significantly lower total number of perfused vessels than in control mice ( $p<0.05$; Figures 9A and 10A,B). L-arginine 
supplementation in arginase-treated mice did not result in improvement of the microcirculation, indicated by a similar total number of perfused vessels or number of perfused vessels per villus (Figures 9A,B and 10D). On the contrary, L-citrulline supplementation in arginase-treated mice was associated with a $\sim 85 \%$ higher total number of perfused vessels (Figures 9A,B and 10F). In addition, the total number of perfused vessels in citrulline + arginase-treated mice did not differ from control mice supplemented with L-citrulline (Figure 9A).

A

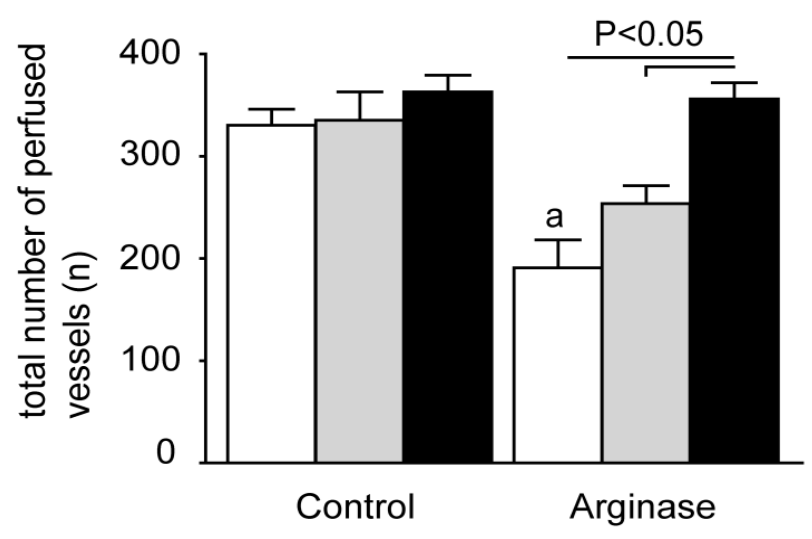

C

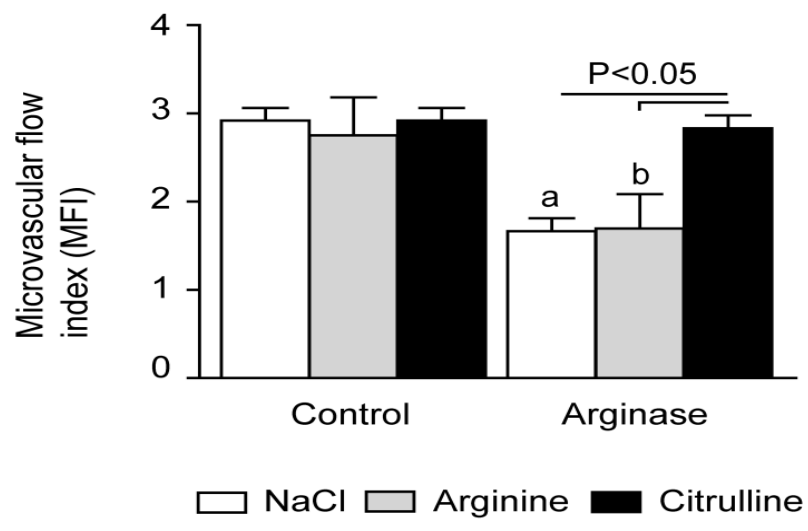

B

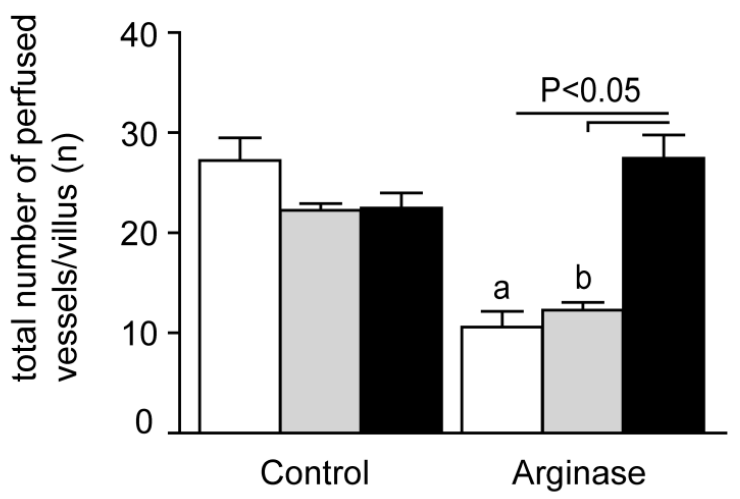

Figure 9. Microcirculatory measurements with side stream dark-field (SDF)-imaging in the jejunal villi. (A) The total number of perfused vessels measured with SDF-imaging in the jejunal villi was significantly decreased in arginase-treated mice compared to the control and after L-citrulline supplementation in arginase-treated mice. (B) The number of perfused vessels per villus was in line with the total number of perfused vessels, as arginase-treated mice exhibited significantly less perfused vessels per villus compared to control mice. L-citrulline supplementation in arginase-treated mice resulted in an increased number of perfused vessels per villus, whereas L-arginine supplementation did not result in an increased in the number of perfused vessels per villus. (C) The microvascular flow index (MFI) was significantly reduced in the arginase- and arginase + arginine-supplemented animals compared to the control and citrulline-treated animals during basal and arginase + citrulline treatment. Significance: ${ }^{\mathrm{a}} p<0.05 v s$. control; ${ }^{\mathrm{b}} p<0.05$ vs. arginine; ${ }^{\mathrm{c}} p<0.05 v s$. arginine + arginase; ${ }^{\mathrm{d}} p<0.05$ vs. citrulline + arginase. 
MFI, the determination of the predominant type of flow in the villi in the four quadrants of the image, was significantly lower in arginase-treated than control mice $(1.7 \pm 0.1$ vs. $2.9 \pm 0.1, p<0.001$; Figure 5C). In addition, L-arginine supplementation did not result in a higher MFI in arginase-treated mice, while arginase-infused L-citrulline supplemented animals had a significantly higher MFI compared to arginase-infused animals alone $(2.8 \pm 0.1$ vs. $1.7 \pm 0.1, p<0.001)$.
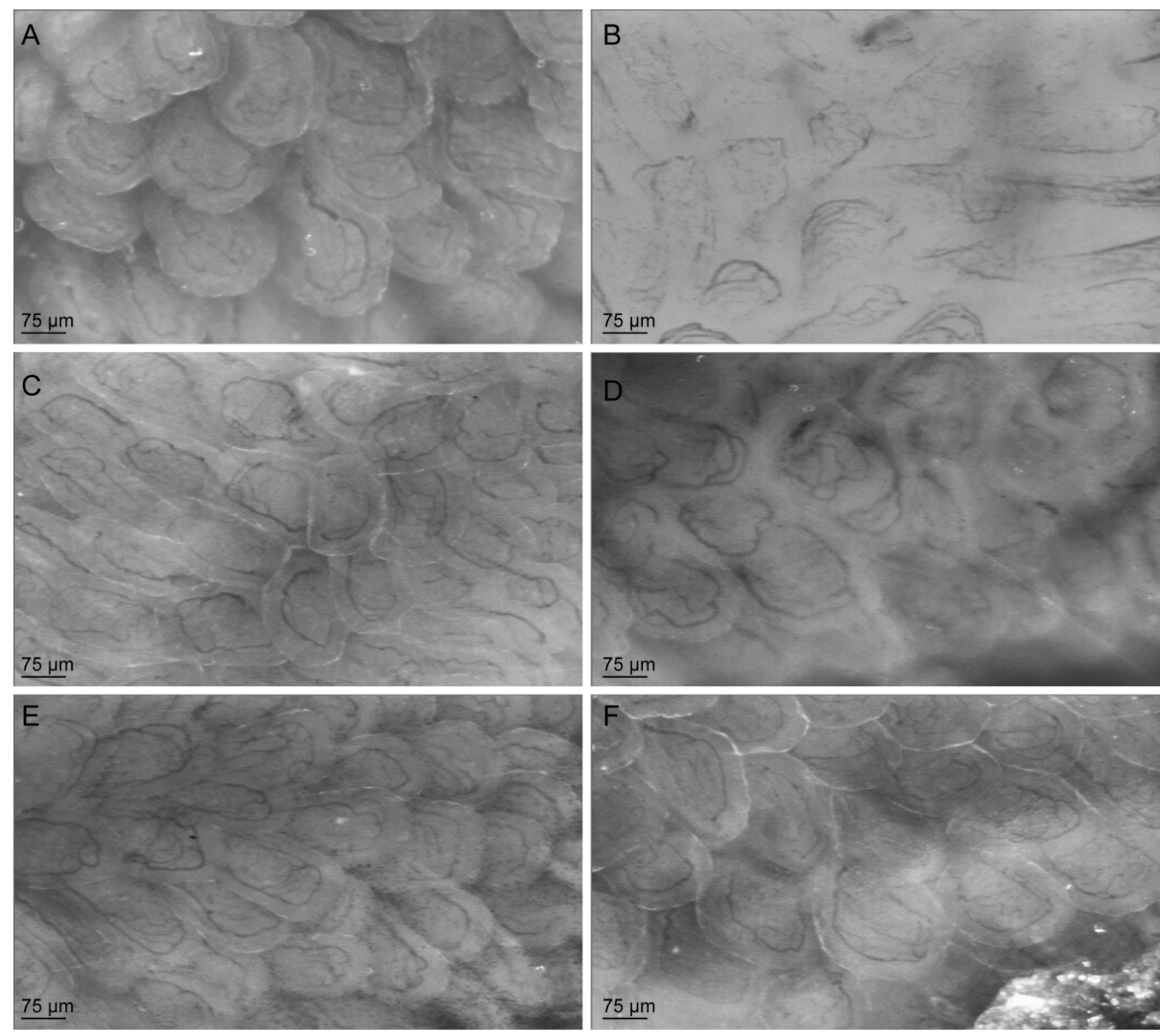

Figure 10. Representative live images of the microcirculatory measurements in jejunal villi with side stream dark-field (SDF)-imaging of control and arginase treated animals with or without L-citrulline or L-arginine supplementation. (A) Representative image of the jejunal microcirculation in a control mouse. (B) Representative image of an arginase-treated mouse, with a decreased number of perfused vessels per villus. (C) Representative image of the jejunal microcirculation in an L-arginine-treated mouse, which shows a comparable perfusion pattern as the control mouse. (D) Representative image of an arginase + L-arginine-treated mouse, which shows no beneficial effect of L-arginine supplementation on the perfusion. (E) Representative live image of an L-citrulline-treated mouse, which also shows a comparable perfusion pattern as the control and L-arginine-treated mouse. (F) Representative image of an arginase + L-citrulline-treated mouse, which shows more perfused vessels per villus compared to arginase and arginase + L-arginine-treated animals. 


\section{Discussion}

To our knowledge, this is the first study comparing the acute effects of L-citrulline and L-arginine supplementation on tissue and systemic arginine availability, NO production and microcirculation in an acute arginine-deficient state. The present study provides new evidence that L-citrulline, but not L-arginine, supplementation improves the microcirculation in an end organ during conditions with arginase-induced acute arginine deficiency by increasing NO production. Our findings may have important consequences for further studies that aim to improve acute dysregulation of arginine metabolism, such as in sickle cell disease [34].

Previous studies have shown that increasing plasma arginine concentrations by supplementing L-arginine resulted in an increased arteriole diameter in the cremaster muscle of transgenic sickle mice [11,35]. In contrast, arginine supplementation did not result in an improved microcirculation or NO production in our previously developed septic model with a prolonged increase in arginase activity and accompanying arginine deficiency [17]. In agreement with our earlier data from the septic model, L-arginine supplementation in this study did not increase local arginine availability, NO production nor the intestinal microcirculation during acutely-enhanced plasma arginase activity.

In addition to sickle cell disease, conditions, such as endotoxemia, hemolysis, sepsis, asthma and liver diseases, are also characterized by an increased plasma arginase activity [2,8,22,36-40]. In these examples, arginase-induced arginine deficiency also resulted in decreased intracellular arginine availability for NO production due to a CAT-mediated exchange of intracellular arginine for extracellular high ornithine concentrations, resulting from the high plasma arginase activity $[17,41,42]$. L-citrulline was suggested as an alternative for enhancing intracellular arginine and NO concentrations, since citrulline is capable of bypassing the arginase activity in the gastro-intestinal tract [43,44]. This bypass effect was also observed in the present study, as the supplemented L-citrulline resulted in a $>2$-fold increase in plasma arginine concentrations during this acutely-enhanced arginase activity. The necessary intracellular or renal conversion of citrulline into arginine may be the underlying beneficial feature of citrulline supplementation versus arginine, as this allows an increase in arginine plasma and tissue concentrations during conditions with enhanced arginine catabolism. Indeed, L-citrulline supplementation also enhanced the ornithine concentrations during this study, which may be the result of the conversion of the circulating arginine derived from citrulline or the diminished conversion of ornithine into citrulline $[45,46]$. On the contrary, the supplemented L-arginine was converted into ornithine as observed in the increased plasma and tissue ornithine concentrations during the basal and experimental condition with enhanced arginase activity. Furthermore, the presence of argininosuccinate synthase (ASS) in endothelial cells allows the cells to use exogenous L-citrulline to increase intracellular arginine for NO production [47-49]. Thus, citrulline can act as a direct vasodilator in the microcirculation [50], which may contribute to the beneficial effects of L-citrulline supplementation on the microcirculation observed in this study. Another benefit of citrulline supplementation is the incomplete hepatic clearance of citrulline, resulting in enhanced citrulline availability from supplementation or endogenous synthesis in the gut, which can be used to enhance de novo arginine synthesis in the kidney [51,52] or in endothelial cells. Interestingly, citrulline supplementation resulted in an increased citrulline concentration in liver tissue, in agreement with a low affinity of the uptake of citrulline in liver. However, the intracellular citrulline 
concentrations in liver tissue were not as high as in renal tissue, which may be explained by an enhanced conversion of citrulline into ornithine and urea as part of the urea cycle.

In one non-controlled pilot study, citrulline enhanced arginine availability and relieved exertional fatigue and dyspnea in sickle cell disease [16]. Thus far, the influence of L-citrulline supplementation on the microcirculation in sickle cell disease remains to be investigated. We previously demonstrated that L-citrulline supplementation increased arginine availability and NO production during a prolonged arginine-deficient state, partly caused by an enhanced arginase activity [17]. In the present study, with an acute enhanced arginase activity, comparable results were observed with L-citrulline supplementation. As observed in this study, citrulline supplementation enhanced the arginine concentration in the kidney 25-fold compared to control conditions, resulting in a significantly higher circulating arginine concentration than in arginine-supplemented animals. This positive enhancement of the plasma arginine concentration was also present in the arginase-treated group, which strengthens our hypothesis that citrulline may be the preferred substrate to increase the arginine availability in arginine-deficient conditions. In addition, gastrointestinal complaints after the intake of large L-arginine amounts are not observed in studies with large oral L-citrulline amounts [43,53-55]. Furthermore, in humans, L-citrulline supplementation is a good therapeutic strategy to combat splanchnic hypoperfusion-induced intestinal compromise in strenuous exercise, as this resulted in an increased number of perfused small sublingual vessels and prevention of splanchnic hypoperfusion and gastrointestinal damage [56].

Additional issues remain to be investigated. The microcirculatory measurements were conducted in the jejunal villi, but not in the liver or renal tissue of these animals, as a limitation of the SDF-imager in this model. The SDF-imager is applied on tissue surfaces, especially mucosa, and measures perfused vessels, as the 530-nm light is absorbed by the hemoglobin in red blood cells [57]. Measurements of the microcirculation in liver and renal tissue with the SDF-imager on the external surface $[58,59]$ is less suitable in this study, as these tissues exhibit a large amount of red blood cells, which prevents the accurate measurement of the microcirculation in the tissues relevant for our study. To visualize the microcirculation in renal tissue [59], the retroperitoneal cavity has to be opened and part of the renal capsule removed, to visualize the renal tissue responsible for the arginine de novo synthesis. This not only results in tissue damage, leading to free-hemoglobin, but also a prolonged surgical procedure, which interferes with the fixed time period of the experiment. As previously observed in conditions with an acute increase in arginase, the gut microcirculation is the first organ system to derange, after which other microcirculatory beds are affected [33,60-62], which led us to the present experimental protocol, which only investigated the microcirculation in the jejunal villi. Therefore, due to technical limitations in this study, the influence of L-citrulline supplementation during an acute arginase-induced arginine deficiency in other vascular beds still needs to be examined. Another limitation of this study is that the effects of an acute arginase-induced arginine deficiency were not investigated in a mouse model of sickle cell disease. Transgenic mouse models to investigate sickle cell disease use mice exhibiting mild and severe pathology with different expression patterns of beta(S)-globin or hemoglobin-S, such as NY1DD mice and Berkeley (BERK) mice [10,11]. Future studies should determine the role of arginase in the acute hemolytic crises in these mice and the beneficial effects of L-citrulline supplementation. 


\section{Conclusions}

In conclusion, our study showed that L-citrulline supplementation resulted in improved microcirculation during an arginase-induced acute arginine-deficiency state by increasing arginine availability and NO production, while these effects were not achieved with L-arginine supplementation.

\section{Acknowledgments}

The authors would like to thank the company Kyowa Hakko USA for providing the L-citrulline.

The authors have declared no conflicts of interests. This study was supported by grants from ZonMw Innovational Research Incentives (VENI 916.76.191) and the European Society of Intensive Care Medicine Eli Lilly Sepsis Elite Award 2008. The funders had no role in the study design, data collection and analysis, decision to publish nor the preparation of the manuscript

\section{Author Contributions}

The authors' responsibilities were as follows; Karolina A.P. Wijnands and Martijn Poeze designed research; Karolina A.P. Wijnands, Kevin W.Y. van Barneveld, Ruben G.J. Visschers, Nadine van den Hoven, Christian J.H. von Wintersdorff and Dennis M. Meesters conducted the research and collected the data; Benjamin Vandendriessche, Anje Cauwels and Peter Brouckaert provided the mice; Karolina A.P. Wijnands, Dennis M. Meesters, and Jacob J. Briedé analyzed the data; Hans M.H. van Eijk and Babs A.F.M. Bessems performed the HPLC measurements, Karolina A.P. Wijnands, Nicole D. Bouvy, Benjamin Vandendriessche, Peter Brouckaert, Anje Cauwels, Wouter H. Lamers and Martijn Poeze drafted the manuscript; Karolina A.P. Wijnands, Wouter H. Lamers and Martijn Poeze had primary responsibility for final content. All authors read and approved the final manuscript.

\section{Conflicts of Interest}

The authors declare no conflict of interest.

\section{References}

1. Waugh, W.H.; Daeschner, C.W.; Files, B.A.; Gordon, D.W. Evidence that L-arginine is key amino acid in sickle cell anemia-A preliminary report. Nutr. Res. 1999, 19, 501-518.

2. Gladwin, M.T.; Kato, G.J. Cardiopulmonary complications of sickle cell disease: Role of nitric oxide and hemolytic anemia. Hematol. Am. Soc. Hematol. Educ. Program 2005, 2005, 51-57.

3. Reiter, C.D.; Gladwin, M.T. An emerging role for nitric oxide in sickle cell disease vascular homeostasis and therapy. Curr. Opin. Hematol. 2003, 10, 99-107.

4. Morris, C.R.; Kato, G.J.; Poljakovic, M.; Wang, X.; Blackwelder, W.C.; Sachdev, V.; Vichinsky, E.P.; Hazen, S.L.; Morris, S.M.; Gladwin, M.T. Dysregulated arginine metabolism, hemolysis-associated pulmonary hypertension, and mortality in sickle cell disease. JAMA 2005, 294, 81-90.

5. Morris, C.R.; Morris, S.M.; Hagar, W.; van Warmerdam, J.; Claster, S.; Kepka-Lenhart, D.; Machado, L.; Kuypers, F.A.; Vichinsky, E.P. Arginine therapy: A new treatment for pulmonary hypertension in sickle cell disease? Am. J. Respir. Crit. Care Med. 2003, 168, 63-69. 
6. Trzeciak, S.; Cinel, I.; Phillip Dellinger, R.; Shapiro, N.I.; Arnold, R.C.; Parrillo, J.E.; Hollenberg, S.M. Resuscitating the microcirculation in sepsis: The central role of nitric oxide, emerging concepts for novel therapies, and challenges for clinical trials. Acad. Emerg. Med. 2008, 15, 399-413.

7. Morris, C.R.; Kuypers, F.A.; Larkin, S.; Sweeters, N.; Simon, J.; Vichinsky, E.P.; Styles, L.A. Arginine therapy: A novel strategy to induce nitric oxide production in sickle cell disease. $B r . J$. Haematol. 2000, 111, 498-500.

8. Morris, S.M. Arginases and arginine deficiency syndromes. Curr. Opin. Clin. Nutr. Metab. Care 2012, 15, 64-70.

9. Darghouth, D.; Koehl, B.; Madalinski, G.; Heilier, J.F.; Bovee, P.; Xu, Y.; Olivier, M.F.; Bartolucci, P.; Benkerrou, M.; Pissard, S.; et al. Pathophysiology of sickle cell disease is mirrored by the red blood cell metabolome. Blood 2011, 117, e57-e66.

10. Dasgupta, T.; Hebbel, R.P.; Kaul, D.K. Protective effect of arginine on oxidative stress in transgenic sickle mouse models. Free Radic. Biol. Med. 2006, 41, 1771-1780.

11. Kaul, D.K.; Zhang, X.; Dasgupta, T.; Fabry, M.E. Arginine therapy of transgenic-knockout sickle mice improves microvascular function by reducing non-nitric oxide vasodilators, hemolysis, and oxidative stress. Am. J. Physiol. 2008, 295, H39-H47.

12. Sullivan, K.J.; Kissoon, N.; Sandler, E.; Gauger, C.; Froyen, M.; Duckworth, L.; Brown, M.; Murphy, S. Effect of oral arginine supplementation on exhaled nitric oxide concentration in sickle cell anemia and acute chest syndrome. J. Pediatr. Hematol. Oncol. 2010, 32, e249-e258.

13. Little, J.A.; Hauser, K.P.; Martyr, S.E.; Harris, A.; Maric, I.; Morris, C.R.; Suh, J.H.; Taylor, J.; Castro, O.; Machado, R.; et al. Hematologic, biochemical, and cardiopulmonary effects of L-arginine supplementation or phosphodiesterase 5 inhibition in patients with sickle cell disease who are on hydroxyurea therapy. Eur. J. Haematol. 2009, 82, 315-321.

14. Windmueller, H.G.; Spaeth, A.E. Source and fate of circulating citrulline. Am. J. Physiol. 1981, 241, E473-E480.

15. Ratner, S.; Petrack, B. The mechanism of arginine synthesis from citrulline in kidney. J. Biol. Chem. 1953, 200, 175-185.

16. Waugh, W.H.; Daeschner, C.W.; Files, B.A.; McConnell, M.E.; Strandjord, S.E. Oral citrulline as arginine precursor may be beneficial in sickle cell disease: Early phase two results. J. Natl. Med. Assoc. 2001, 93, 363-371.

17. Wijnands, K.A.P.; Vink, H.; Briedé, J.J.; van Faassen, E.E.; Lamers, W.H.; Buurman, W.A.; Poeze, M. Citrulline a more suitable substrate than arginine to restore no production and the microcirculation during endotoxemia. PLOS ONE 2012, 7, e37439.

18. Schwedhelm, E.; Maas, R.; Freese, R.; Jung, D.; Lukacs, Z.; Jambrecina, A.; Spickler, W.; Schulze, F.; Boger, R.H. Pharmacokinetic and pharmacodynamic properties of oral L-citrulline and L-arginine: Impact on nitric oxide metabolism. Br. J. Clin. Pharmacol. 2008, 65, 51-59.

19. Bruins, M.J. L-Arginine Treatment during Acute and Longterm Endotoxemia in the Pig: Effects on Jejunal Motility and Interorgan Protein, Arginine and Nitric Oxide Metabolism. Ph.D. Thesis, Maastricht University, Maastricht, The Netherlands, 2001; pp. 1-243.

20. Scavella, A.; Leiva, L.; Monjure, H.; Zea, A.H.; Gardner, R.V. Effect of L-arginine supplementation on immune responsiveness in patients with sickle cell disease. Pediatr. Blood Cancer 2010, 55, $318-323$. 
21. Van Eijk, H.M.; Rooyakkers, D.R.; Deutz, N.E. Rapid routine determination of amino acids in plasma by high-performance liquid chromatography with a 2-3 microns spherisorb ods ii column. J. Chromatogr. 1993, 620, 143-148.

22. Morris, C.R.; Poljakovic, M.; Lavrisha, L.; Machado, L.; Kuypers, F.A.; Morris, S.M., Jr. Decreased arginine bioavailability and increased serum arginase activity in asthma. Am. J. Respir. Crit. Care Med. 2004, 170, 148-153.

23. Verrey, F.; Closs, E.I.; Wagner, C.A.; Palacin, M.; Endou, H.; Kanai, Y. Cats and hats: The SLC7 family of amino acid transporters. Pflug. Arch. 2004, 447, 532-542.

24. Fotiadis, D.; Kanai, Y.; Palacin, M. The SLC3 and SLC7 families of amino acid transporters. Mol. Asp. Med. 2013, 34, 139-158.

25. Closs, E.I.; Boissel, J.P.; Habermeier, A.; Rotmann, A. Structure and function of cationic amino acid transporters (cats). J. Membr. Biol. 2006, 213, 67-77.

26. Yeramian, A.; Martin, L.; Serrat, N.; Arpa, L.; Soler, C.; Bertran, J.; McLeod, C.; Palacin, M.; Modolell, M.; Lloberas, J.; et al. Arginine transport via cationic amino acid transporter 2 plays a critical regulatory role in classical or alternative activation of macrophages. J. Immunol. 2006, 176, 5918-5924.

27. Van Faassen, E.E.; Koeners, M.P.; Joles, J.A.; Vanin, A.F. Detection of basal no production in rat tissues using iron-dithiocarbamate complexes. Nitric Oxide 2008, 18, 279-286.

28. Groner, W.; Winkelman, J.W.; Harris, A.G.; Ince, C.; Bouma, G.J.; Messmer, K.; Nadeau, R.G. Orthogonal polarization spectral imaging: A new method for study of the microcirculation. Nat. Med. 1999, 5, 1209-1212.

29. Spronk, P.E.; Ince, C.; Gardien, M.J.; Mathura, K.R.; Oudemans-van Straaten, H.M.; Zandstra, D.F. Nitroglycerin in septic shock after intravascular volume resuscitation. Lancet 2002, 360, 1395-1396.

30. Dhiman, R.; Yusif, R.; Nabar, U.; Albaqali, A. Images of interest. Gastrointestinal: Ischemic enteritis and sickle cell disease. J. Gastroenterol. Hepatol. 2004, 19, 1318.

31. De Backer, D.; Hollenberg, S.; Boerma, C.; Goedhart, P.; Buchele, G.; Ospina-Tascon, G.; Dobbe, I.; Ince, C. How to evaluate the microcirculation: Report of a round table conference. Crit. Care 2007, 11, R101.

32. Boerma, E.C.; Mathura, K.R.; van der Voort, P.H.; Spronk, P.E.; Ince, C. Quantifying bedside-derived imaging of microcirculatory abnormalities in septic patients: A prospective validation study. Crit. Care 2005, 9, R601-R606.

33. Verdant, C.L.; de Backer, D.; Bruhn, A.; Clausi, C.M.; Su, F.; Wang, Z.; Rodriguez, H.; Pries, A.R.; Vincent, J.L. Evaluation of sublingual and gut mucosal microcirculation in sepsis: A quantitative analysis. Crit. Care Med. 2009, 37, 2875-2881.

34. Schnog, J.J.; Jager, E.H.; van der Dijs, F.P.; Duits, A.J.; Moshage, H.; Muskiet, F.D.; Muskiet, F.A. Evidence for a metabolic shift of arginine metabolism in sickle cell disease. Ann. Hematol. 2004, $83,371-375$.

35. Kaul, D.K.; Liu, X.D.; Fabry, M.E.; Nagel, R.L. Impaired nitric oxide-mediated vasodilation in transgenic sickle mouse. Am. J. Physiol. 2000, 278, H1799-H1806.

36. Coman, D.; Yaplito-Lee, J.; Boneh, A. New indications and controversies in arginine therapy. Clin. Nutr. 2008, 27, 489-496. 
37. Mack, A.K.; Kato, G.J. Sickle cell disease and nitric oxide: A paradigm shift? Int. J. Biochem. Cell Biol. 2006, 38, 1237-1243.

38. Luiking, Y.C.; Poeze, M.; Ramsay, G.; Deutz, N.E. Reduced citrulline production in sepsis is related to diminished de novo arginine and nitric oxide production. Am. J. Clin. Nutr. 2009, 89, $142-152$.

39. Luiking, Y.C.; Poeze, M.; Ramsay, G.; Deutz, N.E. The role of arginine in infection and sepsis. JPEN J. Parenter. Enter. Nutr. 2005, 29, S70-S74.

40. Jeyabalan, G.; Klune, J.R.; Nakao, A.; Martik, N.; Wu, G.; Tsung, A.; Geller, D.A. Arginase blockade protects against hepatic damage in warm ischemia-reperfusion. Nitric Oxide 2008, 19, 29-35.

41. Goodwin, B.L.; Solomonson, L.P.; Eichler, D.C. Argininosuccinate synthase expression is required to maintain nitric oxide production and cell viability in aortic endothelial cells. J. Biol. Chem. 2004, 279, 18353-18360.

42. Durante, W.; Johnson, F.K.; Johnson, R.A. Arginase: A critical regulator of nitric oxide synthesis and vascular function. Clin. Exp. Pharmacol. Physiol. 2007, 34, 906-911.

43. Curis, E.; Nicolis, I.; Moinard, C.; Osowska, S.; Zerrouk, N.; Benazeth, S.; Cynober, L. Almost all about citrulline in mammals. Amino Acids 2005, 29, 177-205.

44. McCarty, M.F. Potential utility of full-spectrum antioxidant therapy, citrulline, and dietary nitrate in the management of sickle cell disease. Med. Hypotheses 2010, 74, 1055-1058.

45. Marini, J.C. Arginine and ornithine are the main precursors for citrulline synthesis in mice. J. Nutr. 2012, 142, 572-580.

46. Marini, J.C.; Didelija, I.C.; Castillo, L.; Lee, B. Plasma arginine and ornithine are the main citrulline precursors in mice infused with arginine-free diets. J. Nutr. 2010, 140, 1432-1437.

47. Flam, B.R.; Eichler, D.C.; Solomonson, L.P. Endothelial nitric oxide production is tightly coupled to the citrulline-no cycle. Nitric Oxide 2007, 17, 115-121.

48. Shen, L.J.; Beloussow, K.; Shen, W.C. Accessibility of endothelial and inducible nitric oxide synthase to the intracellular citrulline-arginine regeneration pathway. Biochem. Pharmacol. 2005, 69, 97-104.

49. Luiking, Y.C.; Hallemeesch, M.M.; de Jonge, W.J.; Lamers, W.H.; Deutz, N.E. Reduced citrulline availability by OTC-deficiency in mice is related to reduced nitric oxide production. Am. J. Physiol. Endocrinol. Metab. 2008, 295, E1315-E1322.

50. Ruiz, E.; Tejerina, T. Relaxant effects of 1-citrulline in rabbit vascular smooth muscle. Br. J. Pharmacol. 1998, 125, 186-192.

51. Hartman, W.J.; Torre, P.M.; Prior, R.L. Dietary citrulline but not ornithine counteracts dietary arginine deficiency in rats by increasing splanchnic release of citrulline. J. Nutr. 1994, 124, 1950-1960.

52. Luiking, Y.C.; Engelen, M.P.; Deutz, N.E. Regulation of nitric oxide production in health and disease. Curr. Opin. Clin. Nutr. Metab. Care 2010, 13, 97-104.

53. Grimble, G.K. Adverse gastrointestinal effects of arginine and related amino acids. J. Nutr. 2007, 137, 1693S-1701S.

54. Moinard, C.; Nicolis, I.; Neveux, N.; Darquy, S.; Benazeth, S.; Cynober, L. Dose-ranging effects of citrulline administration on plasma amino acids and hormonal patterns in healthy subjects: The citrudose pharmacokinetic study. Bri. J. Nutr. 2008, 99, 855-862. 
55. Vissers, Y.L.; Debats, I.B.; Luiking, Y.C.; Jalan, R.; van der Hulst, R.R.; Dejong, C.H.; Deutz, N.E. Pros and cons of L-arginine supplementation in disease. Nutr. Res. Rev. 2004, 17, 193-210.

56. Van Wijck, K.; Wijnands, K.A.; Meesters, D.M.; Boonen, B.; van Loon, L.J.; Buurman, W.A.; Dejong, C.H.; Lenaerts, K.; Poeze, M. L-citrulline improves splanchnic perfusion and reduces gut injury during exercise. Med. Sci. Sports Exerc. 2014, 46, 2039-2046.

57. Elbers, P.W.; Ince, C. Mechanisms of critical illness--classifying microcirculatory flow abnormalities in distributive shock. Crit. Care Lond. Engl. 2006, 10, 221.

58. Cerny, V.; Turek, Z.; Parizkova, R. In situ assessment of the liver microcirculation in mechanically ventilated rats using sidestream dark-field imaging. Physiol. Res. 2009, 58, 49-55.

59. Liberatore, A.M.A.; Vieira, J.C.; Almeida-Filho, J.; Tedesco, R.C.; Koh, I.H.J. Evaluation by videomicroscopy (SDF) of the renal cortex microcirculation and convoluted tubules in acute renal failure during severe sepsis. Experimental study. Intensiv. Care Med. Exp. 2014, 2, 8.

60. Derikx, J.P.; Poeze, M.; van Bijnen, A.A.; Buurman, W.A.; Heineman, E. Evidence for intestinal and liver epithelial cell injury in the early phase of sepsis. Shock Augusta Ga 2007, 28, 544-548.

61. Stechmiller, J.K.; Treloar, D.; Allen, N. Gut dysfunction in critically ill patients: A review of the literature. Am. J. Crit. Care 1997, 6, 204-209.

62. McCuskey, R.S. Hepatic and splanchnic microvascular responses to inflammation and shock. Hepatogastroenterology 1999, 46, 1464-1467.

(C) 2015 by the authors; licensee MDPI, Basel, Switzerland. This article is an open access article distributed under the terms and conditions of the Creative Commons Attribution license (http://creativecommons.org/licenses/by/4.0/). 